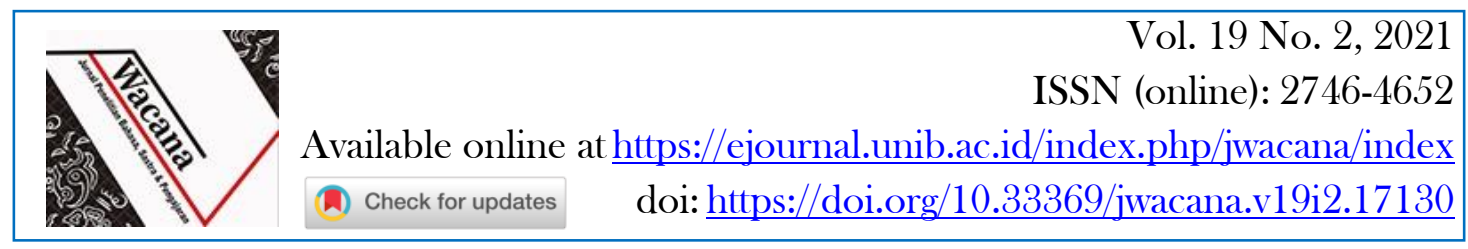

\title{
MENINGKATKAN KEMAMPUAN READING COMPREHENSIONPADA MATA KULIAH ACADEMIC READING MENGGUNAKAN STRATEGI SENTENCE DECOMPOSITION
}

\author{
'Zahrida, ${ }^{2}$ Elfrida \\ ${ }^{1.2}$ Universitas Bengkulu \\ Surel: zahrida@unib.ac.id, $\underline{\text { mrs.elfrida@gmail.com² }}$
}

\begin{abstract}
Abstrak
Penelitian ini merupakan penelitian tindakan kelas yang dilakukan dengan menerapkan Sentence Decomposition pada mata kuliah Academic Reading. Tujuan penelitian ini adalah untuk menginvestigasi apakah strategi Sentence Decomposition dapat meningkatkan kemampuan mahasiswa dalam memahami reading text. Penelitian ini dilaksanakan pada mahasiswa semester III program studi Pendidikan Bahasa Inggris Universitas Bengkulu yang sedang mengambil mata kuliah Academic Reading. Jumlah peserta dalam penelitian ini adalah 43 orang. Penelitian ini terdiri dari dua siklus dan setiap siklus terdiri dari 3 pertemuan. Fase-fase penelitian meliputi perencanaan, pelaksanaan, observasi, dan refleksi. Instrumen yang digunakan adalah tes, lembar observasi/ceklis, dan modul. Hasil tes siklus 2 pada penelitian ini menunjukkan bahwa mahasiswa yang memperoleh nilai lebih atau sama dengan 70 meningkat menjadi $86 \%$ atau meningkat sebanyak $14 \%$ dibandingkan hasil tes siklus 1 . Hasil ini mengindikasikan bahwa indikator kesuksesan telah tercapai yang berarti strategi Sentence Decomposition terbukti dapat meningkatkan kemampuan mahasiswa memahami teks.
\end{abstract}

Kata-kata kunci: sentence decomposition, reading text, reading comprehension, strategi

\begin{abstract}
This research is a classroom action research conducted by applying Sentence Decomposition in Academic Reading courses. The purpose of this study is to investigate whether the Sentence Decomposition strategy can improve students' ability to understand reading text. This research was conducted on the third semester students of the Bengkulu University English Education study program who were taking the Academic Reading course. The number of participants in this study was 43 people. This study consisted of two cycles and each cycle consisted of 3 meetings. The research phases include planning, implementation, observation, and reflection. The instruments used are tests, observation sheets/checklists, and modules. The results of the cycle 2 test in this study showed that students who scored more than or equal to 70 increased to $86 \%$ or increased by $14 \%$ compared to the results of the cycle 1 test. students understand the text.
\end{abstract}

Keywords: sentence decomposition, reading text, reading comprehension, strategi

PENDAHULUAN

Reading text adalah sebuah teks yang di dalamnya berisi tentang sebuah peristiwa dan informasi-informasi. Reading comprehension adalah membaca dengan tujuan mendapatkan pemahaman yang mendalam dan menyeluruh. Mempelajari dan menguasai reading comprehension sangat penting agar mahasiswa mampu memahami dan lebih lanjut menganalisis sebuah teks. Namun tidak sedikit mahasiswa yang merasa kesulitan untuk mempelajari dan menguasainya karena 
terhambat berbagai kendala misalnya keterbatasan kosa kata yang dimiliki, sulitnya berkonsentrasi dalam membaca teks bahasa Inggris, tidak memahami grammar dengan baik, dan lain sebagainya.

Berdasarkan pengalaman peneliti, salah satu permasalahan yang timbul dalam pembelajaran pada mata kuliah Reading adalah kesulitan mahasiswa memahami kalimat-kalimat rumit dan kompleks, seperti kalimat pasif, compound sentence dan clauses. Sedangkan pemahaman membaca kalimat mempengaruhi kemampuan mahasiswa memahami seluruh teks. Compound sentence dan clauses adalah kalimat majemuk yang terdiri dari gabungan kalimat tunggal. Dalam reading text kalimat yang disusun biasanya tidak hanya berbentuk sederhana, yaitu terdiri dari subyek, predikat, dan obyek, namun seringkali terdapat banyak penambahan kata seperti clause, adverb, dan adjective untuk menambah informasi pada kalimat. Pada kalimat pasif terdapat pemutarbalikan logika, dimana subyek kalimat aktif menjadi obyek kalimat pasif, dan sebaliknya; dan pada struktur kalimat pasif terdapat perbedaan dengan kalimat aktif. Perbedaan struktur, penambahan kata, dan clause inilah yang sering membuat mahasiswa kesulitan menangkap makna atau inti kalimat. Seperti contoh berikut ini yang dikutip dari novel Charles Dickens berjudul Nicholas Nickleby.

There once lived, in a sequestered part of the country of Devonshire, one Mr. Godfrey Nickleby: a worthy gentleman, who, taking it into his head rather late in life that he must get married, and not being young enough or rich enough to aspire to the hand of a lady of fortune, had wedded an old flame out of mere attachment, who in her turn had taken him for the same reason.

Inti kalimat diatas sebenarnya adalah Godfrey Nickleby had wedded an old flame out of mere attachment. Namun karena banyak terdapat clause dan keterangan tambahan maka kalimat menjadi kompleks dan harus dibaca dengan seksama untuk memahami maksud kalimat tersebut. Hal inilah yang menjadi kesulitan mahasiswa dalam reading comprehension.

Dalam rangka mengatasi permasalahan ini, diperlukan strategi mengajar yang bisa membantu meningkatkan kemampuan mahasiswa memahami reading text. Penelitian ini mengajukan strategi Sentence Decomposition untuk memecahkan masalah diatas. Kame'enui, Carnine, \& Dixon (2002) menjelaskan "sentence decomposition or segmentation involves breaking a syntactically complex sentence down into simpler sentence" (dekomposisi kalimat atau segmentasi yaitu memecah kalimat kompleks menjadi kalimat yang lebih sederhana). Beberapa ahli mengakui prosedur ini ideal untuk memahami kalimat kompleks pada reading text (Paul \& Norbury, 2012; Scott \& Balthazar, 2010; Wallach \& Miller, 1988). Pada strategi ini fokus instruktur adalah pada kalimat yang dianggap sulit, kemudian mengarahkan mahasiswa untuk memecah-mecah kalimat tersebut berdasarkan kalimat tunggal, clause, dan phrase agar lebih mudah dipahami.

Strategi ini diharapkan dapat menjadi solusi permasalahan mahasiswa dalam pembelajaran reading comprehension. Selanjutnya strategi ini menerapkan student-centered (pembelajaran berpusat pada mahasiswa) karena instruktur disini hanya bertugas mengarahkan, memandu, dan melatih mahasiswa untuk menganalisis kalimat. Hal ini diharapkan juga dapat memotivasi mahasiswa belajar mandiri sehingga suasana pembelajaran menjadi menyenangkan.

Penelitian ini dilakukan pada mata kuliah Academic Reading. Subyek penelitian adalah mahasiswa semester III kelas B program studi Pendidikan Bahasa Inggris Universitas Bengkulu angkatan 2019/2020.

\section{KAJIAN TEORI}

\section{Reading Skill (keterampilan membaca)}

Reading adalah salah satu keterampilan yang harus dikuasai oleh siswa yang mempelajari bahasa Inggris. Reading adalah salah satu hal yang paling penting dalam pembelajaran. Menurut Agustina (2008), reading terdiri dari beberapa proses, yaitu: pengamatan simbol-simbol bacaan, memahami arti materi reading, merespon materi reading baik secara positif maupun negative, dan terakhir menarik kesimpulan pesan apa yang ingin disampaikan melalui materi reading tersebut.

Ada beberapa ahli yang menjelaskan mengenai definisi dari reading comprehension. Nurhadi (2004) mengatakan bahwa reading comprehension adalah suatu proses menggunakan sintaks, semantik, dan informasi retorik yang terkandung di dalam teks tertulis yang disusun di alam pikiran manusia dengan menggunakan pengetahuan, kemampuan kognitif, dan akal pikiran. Suyoto (2008) menjelaskan bahwa reading comprehension adalah kemampuan membaca ide utama, detildetil penting, dan memahami secara keseluruhan. Berdasarkan penjelasan para ahli diatas, dapat disimpulkan bahwa reading comprehension adalah kemampuan memahami secara menyeluruh suatu reading text. 


\section{Kalimat Kompleks dan Permasalahan Pemahamannya}

Dalam bahasa Inggris ada 4 struktur kalimat yang dianggap sulit dipahami bagi pembaca, yaitu (a) kalimat dengan konstruksi pasif, (b) adverbial clauses dengan keterangan waktu dan kata sambung, (c) relative/adjective clauses, dan (d) kalimat kompleks dengan lebih dari dua clauses (Eisenberg, 2006; Merrit \& Culatta, 1998; Owens, 2016; Paul \& Norbury, 2012; Scott, 2009; Snow \& Kim, 2010).

\section{Kalimat dengan Konstruksi Pasif}

Kalimat dikatakan berkonstruksi pasif bila Subyek kalimat berasal dari kalimat aktif. Contohnya, "The bear was tricked by the fox" (beruang ditipu rubah). Pada kalimat ini sebenarnya yang menjadi obyek penderita (penerima tindakan) adalah "the bear" dan pelaku kalimat sesungguhnya adalah "the fox," namun posisi frasa-frasa tersebut berkebalikan dengan posisi di kalimat aktif. Bentuk kalimat ini akan lebih mudah dipahami pembaca bila ditulis dalam kalimat aktif: "The fox tricked the bear."

Untuk memahami struktur kalimat ini, pembaca harus mengetahui fungsi kata-kata seperti "was" dan "by" yang beroperasi di kalimat pasif. Bila terjadi kesalahanan pemahaman, kalimat "the bear was tricked by the fox" bisa diartikan "beruang menipu rubah."

Kesalahan pemahaman bisa menimbulkan kebingungan pada pembaca karena tidak sesuai dengan pengetahuan yang mereka dapat. Contohnya, kalimat "The deer was killed by the lion" (rusa dibunuh singa). Bila pembaca memahami kalimat ini sebagai rusa membunuh singa, maka akan terjadi kebingungan karena tidak sesuai dengan logika pembaca.

\section{Adverbial Clauses dengan Keterangan waktu dan Kata Sambung}

Clause atau klausa adalah sekumpulan kata yang memiliki Subyek dan Predikat. Klausa terdiri dari induk kalimat (main clause) dan anak kalimat (dependent clause). Induk kalimat dapat berdiri sendiri, sedangkan anak kalimat harus melekat dengan induk kalimat baru mendapatkan arti. Gabungan induk dan anak kalimat inilah yang disebut dengan kalimat kompleks. Contoh kalimat kompleks adalah "Before he got into bed, he checked his pocket" (Sebelum ia tidur, ia mengecek sakunya). "he checked his pocket" adalah induk kalimat yang mempunyai makna yang lengkap. Sedangkan kalimat "before he got into bed" adalah anak kalimat yang tidak dapat berdiri sendiri melainkan harus dilekatkan pada induk kalimatnya. Jenis kalimat ini disebut dengan adverbial clauses, atau anak kalimat yang berperan sebagai kata keterangan (Justice \& Ezell, 2002).

Kalimat jenis adverbial clauses bisa membingungkan pembaca, terutama bagi pembaca yang belum memahami tentang kata keterangan waktu dan sebab akibat (temporal and causal adverb). Kesalahan pemahaman pada keterangan waktu, misalnya pada kalimat "Before you eat dinner, wash the dishes" (sebelum kamu makan, cuci dulu peralatan makannya). Bila terjadi kesalahan pemahaman, kalimat diatas bisa dimaknai sebagai "cuci peralatan makan dahulu sesudah makan." Hal ini bisa terjadi karena posisi klausa "before you eat dinner" adalah di awal kalimat, dan adanya logika pembaca bahwa yang biasanya terjadi adalah makan dahulu baru setelahnya mencuci peralatan makan.

\section{Kalimat yang Terdiri dari Lebih dari Dua Klausa}

Kalimat kompleks adalah kalimat yang sekurang-kurangnnya terdiri dari 2 klausa (clauses) atau 2 kalimat yang dihubungkan dengan kata hubung (compound sentence), atau gabungan dari clauses dan compound sentence. Pembaca yang masih kurang memahami rumitnya tata kalimat kompleks dalam bahasa Inggris akan mengalami kesulitan memahami reading text yang mengandung kalimat jenis ini. Contoh kalimat: "Because water molecules cling to each other like tiny magnets, a drop of water can stay in one piece, even as it falls through the air." Ke-26 kata pada kalimat kompleks ini mengandung 1 induk kalimat (a drop of water can stay in one piece) dan 2 adverbial clause ("Because water molecules cling to each other like tiny magnets" dan "even as it falls through the air"). Kalimat jenis ini sering menimbulkan kesulitan pada pembaca untuk menentukan apa sebenarnya inti yang dibicarakan pada kalimat ini.

\section{Relative/Adjective Clauses}

Relative/adjective clauses klausa yang bertindak sebagai kata sifat (adjective) dengan menyediakan informasi mengenai subyek atau obyek induk kalimat (Justice \& Ezell, 2002). Relative clause seringkali diawali dengan relative pronoun seperti that, who, atau which. Contoh kalimat: "But 
in the cold air, water molecules that cling to particles from tiny ice crystals." Pada kalimat ini, relative clause "that cling to particles from tiny ice crystals" memberi informasi tambahan pada subyek "water molecules." Relative clause ini terletak di tengah-tengah induk kalimat, memisahkan letak induk kalimat tersebut di dalam kalimat "water molecules..........form tiny ice crystals." Posisi relative clause ini sering menjadi penyebab kebingungan pembaca dalam memahami kalimat, terutama untuk relative clause yang berisi kalimat yang panjang. Relative clause banyak dijumpai pada reading text jenis naratif dan eksposisi (Scott \& Balthazar, 2010).

\section{Strategi Mengajar pada Reading Text}

Menurut Zipoli (2017) ada beberapa teknik mengajar yang dapat digunakan untuk meningkatkan pemahaman mahasiswa terhadap reading text, terutama untuk kalimat-kalimat rumit seperti kalimat kompleks, yaitu:

\section{Directed Question}

Teknik ini menggunakan pertanyaan untuk meningkatkan pemahaman pembelajar. Teknik ini diakui efektif dalam pembelajaran reading. Carnine dkk (2010) memaparkan rangkaian instruksi berbentuk pertanyaan. Contoh: kalimat "Diego found a cat" (Diego menemukan seekor kucing).

Instruktur : What was found? (Apa yang ditemukan?)

Pembelajar : A cat.

Instruktur : Who did the finding? (Siapa yang menemukan?)

Pembelajar : Diego.

\section{Sentence Decomposition}

Sentence decomposition adalah teknik membaca dengan memecah atau memilah kalimat ke dalam clauses atau phrases. Teknik ini bertujuan untuk mencari inti dari kalimat yang dimaksud. Pembelajar dilatih untuk menentukan bagian mana yang merupakan ide utama dari clauses dan compound sentence. Contoh: "The teacher taught spiritfully and the students studied diligently eventhough the day was so hot"

Instruktur : Berapa banyak induk kalimat tersebut?

Pembelajar : Dua. "the teacher taught spiritfully" dan "the students studied diligently."

Instruktur : Yang manakah anak kalimat pada kalimat tersebut?

Pembelajar : "eventhough the day was so hot."

Selain strategi mengajar di atas masih banyak strategi reading comprehension lain yang telah diajukan oleh para ahli. Salah satunya adalah Guided Reading Strategy (GRS). Fountas dan Pennel dalam Syahputera (2016) menjelaskan bahwa GRS adalah metode kelompok-kelompok reading kecil dengan level yang berbeda-beda yang mengikuti instruksi yang didisain untuk meningkatkan profisiensi siswa di dalam kelompok tersebut. Pada strategi ini, instruktur memilih teks-teks yang sesuai dengan level profisiensi siswa. Mahasiswa mendiskusikan dan terkadang menulis teks yang secara cermat dipilih oleh instruktur sesuai level.

Beberapa penelitian yang berhubungan dengan strategi mengajar untuk meningkatkan kemampuan membaca telah dilakukan oleh beberapa peneliti, yaitu Supiningsih (2017) yang menggunakan strategi Choral Reading dan Syahputera (2016) yang menggunakan Guided Reading Strategy (GRS). Studi-studi tersebut menunjukkan bahwa kemampuan mahasiswa dalam reading comprehension meningkat melalui penerapan strategi pada kelas membaca atau reading.

\section{Metode Penelitian}

Penelitian ini adalah Penelitian Tindakan Kelas (PTK) yang bertujuan meningkatkan proses mengajar dan belajar. Penelitian ini diharapkan bisa memberi alternatif pada strategi pembelajaran mata kuliah Academic Reading.

\section{Prosedur Penelitian}

Penelitian ini direncanakan dilaksanakan dalam dua siklus yang masing-masing siklus terdiri dari tiga pertemuan. Siklus kedua hanya akan dilaksanakan bila siklus pertama belum mencapai target. Tahapan-tahapan penelitian yang akan dilakukan adalah:

\section{Siklus I}


1) Perencanaan

Pada tahap ini peneliti merencanakan bagaimana mengimplementasi strategi Sentence Decomposition di dalam kelas Academic Reading program studi Pendidikan Bahasa Inggris. Perencanaan meliputi mendesain rencana pembelajaran, menyiapkan modul yang berisikan materimateri reading text yang yang akan diimplementasikan, menyiapkan ceklis observasi kegiatan mengajar dosen dan belajar mahasiswa yang nanti akan dilakukan oleh kolaborator, merancang jadwal penelitian, dan merancang alat evaluasi.

\section{Pelaksanaan}

Pada tahap ini peneliti mengimplementasi strategi Sentence Decomposition di dalam kelas. Pada pertemuan pertama di siklus 1 peneliti menerangkan strategi yang akan dïmplementasikan dan melaksanakan pembelajaran menggunakan strategi Sentence Decomposition di dalam kelas Academic Reading dengan melatih dan mengarahkan mahasiswa menggunakan strategi ini agar memahami reading text dengan baik. Pada pertemuan kedua peneliti mengimplementasikan kembali strategi ini dengan materi yang berbeda. Pada pertemuan ketiga peserta diberikan tes untuk menguji keberhasilan penerapan strategi Sentence Decomposition di dalam kelas Academic Reading.

\section{Observasi}

Pada saat pengimplementasian strategi Sentence Decomposition di dalam kelas Academic Reading, peneliti dan kolaborator melakukan observasi selama proses belajar mengajar. Peneliti dan kolaborator mencatat hal-hal yang dianggap perlu selama penelitian.

\section{Refleksi}

Setelah mendapatkan data dari tes dan observasi kolaborator, peneliti dan kolaborator menganalisis data untuk memutuskan apakah pembelajaran berhasil atau tidak, memutuskan apakah siklus kedua akan dilakukan atau tidak, mendiskusikan kelemahan-kelemahan yang telah dilakukan, dan bila ada, membuat rencana perbaikan untuk siklus berikutnya.

\section{Siklus II}

Siklus ini merupakan kelanjutan dari siklus I. Pada siklus ini tahapan yang dilakukan sama dengan siklus I, namun kelemahan-kelemahan yang ada di siklus sebelumnya akan diperbaiki pada siklus ini. Penelitian ini dilakukan pada kelas Academic Reading dengan subyek penelitian mahasiswa semester III program studi Pendidikan Bahasa Inggris Universitas Bengkulu sebanyak 43 partisipan. Waktu penelitian dilaksanakan pada bulan September sampai dengan Oktober 2020.

\section{Teknik Pengumpulan Data}

Data untuk penelitian ini diambil menggunakan data kuantitatif yaitu dari tes yang diujikan di tiap akhir siklus dan data kualitatif yang didapat dari hasil observasi kolaborator.

\section{Instrumen Penelitian}

Dalam pengumpulan data ada beberapa instrumen yang digunakan, yaitu:

a. Tes dilakukan pada akhir siklus dalam bentuk reading text and exercises. Pada model tes ini mahasiswa akan diminta menjawab pertanyaan berdasarkan teks dalam berbagai bentuk pertanyaan seperti essay, pilihan berganda, dan lain-lain yang bertujuan menilai pemahaman mahasiswa terhadap reading text yang diujikan setelah mendapatkan tindakan strategi Sentence Decomposition.

b. Observasi/ceklis dan catatan dilakukan dengan kolaborator yang mengamati berjalannya proses belajar-mengajar. Hasil observasi yang berupa ceklis dan catatan digunakan untuk mengetahui hal-hal yang penting, motivasi peserta, juga kekuatan dan kelemahan pengajar dalam proses pembelajaran.

c. Modul yang dipersiapkan untuk mata kuliah Academic Reading ini berisi materi-materi yang dipelajari selama pembelajaran pada setiap pertemuan. Modul mata kuliah ini memuat reading text dengan berbagai tema yang berhubungan dengan tulisan-tulisan ilmiah baik berupa artikel, jurnal maupun buku.

\section{Analisis Data}


Data penelitian ini dianalisis dengan menggunakan data tes. Data tes yang digunakan dalam penelitian ini adalah nilai masing-masing dan nilai rata-rata mahasiswa. Indikator keberhasilan penelitian ini adalah:

a. $75 \%$ skor tes mahasiswa berada pada kategori baik yaitu $\geq 70$.

b. Mahasiswa mampu memahami kalimat-kalimat kompleks pada berbagai jenis teks.

\section{Hasil Penelitian dan Pembahasan}

Penelitian ini merupakan Penelitian Tindakan Kelas yang dilakukan berdasarkan teori Kemmis and McTagart (1988). Penelitian ini dilakukan dalam 2 siklus. Sebagai akibat terjadinya pandemik COVID 19, maka penelitian ini dilakukan dengan menggunakan media online yaitu Google Classroom pada menu Forum. Berdasarkan hasil field-note pada siklus pertama, sebagian besar partisipan termotivasi mengikuti pembelajaran. Walaupun ada beberapa partisipan yang masih mendapat kesulitan memahami materi, secara umum partisipan aktif dan mampu menganalisis teks sesuai instruksi peneliti. Hasil tes siklus 1 menunjukkan bahwa 31 atau 72\% partisipan mendapat nilai lebih dari 70. Namun, peneliti dan kolaborator memutuskan indikator kesuksesan masih belum tercapai. Berdasarkan field-note ada beberapa catatan yang perlu diperhatikan. Pertama, walaupun sebagian besar mahasiswa mampu mengaplikasikan strategi Sentence Decomposition, masih ada mahasiswa yang mengalami kesulitan. Hal ini terjadi karena pembelajaran menggunakan media online memiliki kelemahan, peneliti mengalami kesulitan mengidentikasi partisipan yang tidak aktif. Kedua, ada jeda waktu yang terjadi antara instruksi peneliti dan respon partisipan. Hal ini akan berbeda pada kelas tatap muka dimana peneliti bisa langsung mengatasi ketika melihat partisipan mengalami masalah. Akibat permasalahan ini partisipan yang bersikap pasif tidak termotivasi melakukan latihan.

Berdasarkan hasil refleksi dan diskusi bersama kolaborator, peneliti perlu melakukan perbaikan mengajar dengan menggunakan strategi Sentence Decomposition pada siklus berikutnya. Berdasarkan hasil field-note di siklus 2, pada saat proses pembelajaran hampir seluruh partisipan aktif dalam menganalisis teks. Pada siklus ini peneliti lebih baik dalam mengontrol kelas yaitu dengan memberi motivasi ke seluruh partisipan. Hal ini memungkinkan karena peneliti sudah mengidentifikasi partisipan yang pasif di siklus 1 dan aktif memberi motivasi pada partisipanpartisipan tersebut. Disamping itu partisipan juga sudah memahami strategi belajar yang dilaksanakan. Kesimpulannya, hasil field-note menunjukkan adanya perbaikan fokus mahasiswa, minat, dan partisipasi partisipan di siklus 2. Disamping itu, hasil tes juga menunjukkan kenaikan signifikan pada nilai mahasiswa dimana partisipan yang memperoleh nilai lebih dari 70 meningkat menjadi 37 atau 86\%. Peneliti dan kolaborator menyimpulkan bahwa ada perbaikan dari siklus 1 ke siklus 2 dan indikator kesuksesan telah tercapai. Oleh karena itu, berdasarkan hasil diskusi peneliti dan kolaborator, peneliti memutuskan menghentikan siklus penelitian.

Terdapat beberapa faktor yang menentukan keberhasilan penelitian ini, yaitu faktor peneliti sebagai dosen pengajar dan faktor mahasiswa sebagai partisipan penelitian. Faktor peneliti adalah manajemen kelas dalam mengontrol kondisi kelas selama proses pembelajaran dan metode mengajar yang berdasarkan analisis kasus atau analisis teks rumit yang lebih kepada student centre. Sedangkan faktor mahasiswa adalah fokus, minat, dan partisipasi mahasiswa. Model student centre juga meningkatkan minat dan motivasi mahasiswa mempelajari materi di mata kuliah Reading. Hal ini sejalan dengan pendapat Scrivener (1994), people learn more by doing themselves (manusia mempelajari lebih banyak dengan berbuat). Disamping itu, ada faktor lain yang ikut mendukung keberhasilan penelitian ini. Partisipan adalah mahasiswa semester III yang juga mengikuti mata kuliah Syntax pada semester penelitian ini dilakukan. Syntax adalah ilmu yang menganalisis unit-unit bahasa mulai dari phrase, clause, compound, phrase and clause, simple sentence dan complex sentence. Hal yang dipelajari di mata kuliah Syntax memberi kontribusi terhadap implementasi strategi penelitian ini, karena seperti menurut Kame'enui, Carnine, \& Dixon (2002) "sentence decomposition or segmentation involves breaking a syntactically complex sentence down into simpler sentence" yaitu strategi ini memecah-mecah kalimat kompleks berdasarkan kalimat tunggal, clause, dan phrase agar lebih mudah dipahami.

\section{Simpulan}

Berdasarkan hasil penelitian, dapat disimpulkan bahwa strategi Sentence Decomposition dapat meningkatkan kemampuan mahasiswa dalam menganalisis kalimat-kalimat rumit dan kompleks pada mata kuliah Academic Reading. Hasil tes menunjukkan bahwa mahasiswa yang memperoleh nilai lebih dari 70 meningkat dari $72 \%$ di siklus 1 menjadi $86 \%$ di siklus 2 . Hasil tes di 
siklus 2 juga menunjukkan bahwa indikator keberhasilan penelitian ini telah tercapai. Kepada peneliti di masa mendatang disarankan dapat menggunakan strategi Sentence Decomposition dengan cara tatap muka di dalam kelas maupun menggunakan media online lain seperti Zoom, Google Meet, dan lain sebagainya untuk meningkatkan kemampuan reading comprehension mahasiswa.

\section{Daftar Pustaka}

Agustina. (2008). Pembelajaran keterampilan membaca. Padang: FBSS UNP.

Carnine, D. W., Silbert, J., Kame'enui, E. J. \& Tarver, S.G. (2010). Direct instruction reading. Excerpts. 4 th \& 5th Ed.

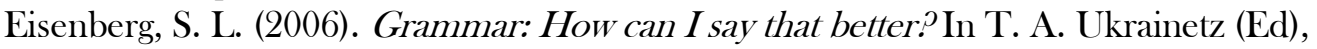
Contextualized language intervention: Scaffolding pre-K-12 literacy achievement (pp. 145194). Eau Claire, WI: Thinking Publications.

Fountas, I.C., \& Pinnel, G.S. (1996). Guided reading: Good first teaching for all children. Portsmouth: Heinemann Publisher.

Justice, L. M., \& Ezell, H. K. (2002). The syntax handbook: Everything you knew about syntax...but forgot. Greenville, SC: Thinking Publication.

Kame'enui, E. J., Carnine, D., \& Dixon, R. C. (2002). Introduction In E. J. Kame'enui, D. W. Carnine, R. C. Dixon, D. C. Simmons, \& M. Coyne (Eds.), Effective teaching strategies that accommodate diverse learners (2nd ed., pp.1-21) Upper Saddle River, NJ: Merril.

Kemmis, Stephen and Robert L. Taggart. (1998). The action research planner (3rd ed). Victoria: Deakin University.

Merritt, D. D., \& Culatta, B. (1998). Language intervention in the classroom. Baltimore, MD: Brookes.

Nurhadi. (2010). Bagaimana meningkatkan kemampuan membaca. Malang: Sinar Baru Algensindo.

Owens, R. E. (2016). Language development: An introduction (9th ed.). Upper Saddle River, NJ: Pearson.

Paul, R. E. (2012). Language disorders from infancy through adolescence: Listening, speaking, reading, writing, and communicating (4th ed.) St. Louis. MO: Mosby.

Scott, C. M., \& Balthazar, C. H. (2010). The grammar of information: Challenges for older students with language impairments. Topics in Language Disorders, 30, 288-307.

Snow, C. E., \& Kim, Y. (2010). Syntactic and discourse structures: What should fourth and fifth graders know and be able to do? Retrieved from http://www.reading.org/libraries/booksupplements/bk767supp-snowkim.pdf

Scrivener, J. (1994). Learning teaching. Oxford: Macmillan Heinemann English Language Teaching.

Supiningsih. (2017). Upaya meningkatkan kemampuan membaca dalam pelajaran bahasa Inggris dengan strategi Choral Reading melalui powerpoint. Jurnal Wacana Akademika Vol. 1 No. $2(2017)$

Suyoto. (2008). Panduan penelitian tindakan kelas. Yogyakarta: Pustaka Book Publisher.

Syahputera, I. (2016). Guided reading strategy to improve reading comprehension. English Education Journal Vol. 7 No. 2 (2016).

Wallach, G. P., \& Miller, L. (1988). Language intervension and academic success. Austin, TX: PRO-ED.

Zipoli, R. P. (2017). Unraveling difficult sentences: Strategies to support reading comprehension. Journal of Intervention in School and Clinic, Vol. 52 (4) 218-227. 